\title{
Vorwort zum vierten Teil
}

Die Spezifik von Plessners philosophischem Einsatz kann durch Vergleiche mit anderen Philosophien zusätzlich konturiert werden, die Plessners sachbezogene Untersuchungsweise, die in den ersten drei Teilen des Buchs dargestellt worden ist, ergänzen.

Die ersten beiden Kapitel des folgenden vierten Teils beschäftigen sich mit Plessners Transformation von Kants Vernunftphilosophie und Nietzsches Lebensphilosophie in den Zivilisationsprozess der personalen Lebenssphäre. Statt Kants Systematik dualistisch zu lesen, setzt Plessner an der integrierenden Rolle der Urteilskraft, der ästhetisch und teleologisch reflektierenden Urteilskraft an, um diese Systematik für die Natur und Geschichte von Lebensprozessen öffnen zu können. Wenn moderne Forschungsunternehmen ganz verschieden nach dem Modell einer reflektierenden Urteilskraft ausgerichtet werden, um zu einer bestimmenden Urteilskraft gelangen zu können, dann kommt es im Resultat nicht zum Widerspruch, sondern zum Widerstreit zwischen ihnen. Um ideologische Verabsolutierungen abwehren zu können, hält Plessner mit Kant an der Bewahrung der Würde von Personen als der philosophisch entscheidenden Werteorientierung fest. In Nietzsches Lebensphilosophie setzt Plessner ebenfalls immanent an, um sie von ihrer eigenen Wirkungsgeschichte zu befreien. Die generöse Souveränität des europäischen Geistes, sich selbst überwinden zu können, holt ihn zivilisatorisch aus dem Wiederholungszwang des Gleichen heraus. Letzterer besteht aus einer Anthropo-Genealogie, die den Menschen mit allen Anthropoiden triebtheoretisch und rassebiologisch gleichsetzt, ohne einen zivilisationsgeschichtlichen Maßstab für die spezifisch personale Transformation von Verdrängungen und Sublimierungen einführen zu können.

Das dritte und vierte Kapitel des vorliegenden vierten Teils sind der Auseinandersetzung mit den verschiedenen Existenzphilosophien von Jaspers und Heidegger gewidmet. Jaspers und Plessner teilen einen „ärztlichen Blick“ (M. Foucault) auf ganze Lebenseinheiten von Subjekt und Objekt respektive von Subjekt und Subjekt in grenzrealisierenden Prozessen mit Grenzsituationen (Jaspers) beziehungsweise Verhaltungsgrenzen (Plessner) in der personalen Lebensführung. Während aber Jaspers die kategorial vergleichbaren Unterscheidungen von ihren jeweils inneren Gliedern her existenziell verwendet, markiert sie Plessner von ihrer leiblichen und öffentlich-mitweltlichen Seite her. Unübertroffen bleibt Jaspers' Erhellung eines je für mich lebensgeschichtlich unvertretbaren Du's in der existentiellen Kommunikation beider als Liebe und Kampf. Der neuere Interpretationsstreit über Heideggers philosophische Anthropologie und Anthropozentrik gibt Gelegenheit, Plessners Kritik an Heideggers 
Anthropozentrismus zu rekonstruieren. Gleichwohl schließt der Gegensatz zwischen Plessners und Heideggers Philosophien strukturelle Gemeinsamkeiten zwischen beiden ein, die darauf zurückgehen, dass beide Max Schelers methodische Revolution der Phänomenologie und seine Figur der Ekstasis (Liebe) zu transformieren unternehmen. Heidegger inszeniert seine Transformation als eine neuerliche kopernikanische Revolution in dem für die dualistische Moderne des Spätkapitalismus charakteristischen Überbietungskampf, obgleich sie sich am Ende nur als eine Philosophie der absoluten Selbstischkeit und des naturalistischen Aberglaubens (Hannah Arendt) offenbart. Plessner hat das ganze Modell der kopernikanischen Revolution für die moderne Serie dualistischer Aushebelungen der personalen Lebenssphäre als Verführung des bürgerlichen Geistes kritisiert. Ihm geht es stattdessen um eine exzentrische Anhebung der Lebensmitte in der personalen Lebenssphäre unter sowohl natur- als auch zivilisationsgeschichtlichen Aspekten.

Die beiden letzten Kapitel des folgenden Teiles vergleichen Deweys und Plessners Naturphilosophien und Philosophien des Politischen miteinander. Wenn die Darwinsche Evolutionstheorie Recht darin hat, dass menschliches Leben aus tierlichem Leben entstanden ist und sich in der Natur halten können muss, dann folgt für beide Philosophen daraus keine biologistische Erklärungsstrategie, sondern eine naturphilosophisch neue und produktive Frage. Wie wird die geistige Lebensform von Menschen in der Natur wirklich möglich, wenn man Geist und Leben in ihrer irreduziblen Qualität versteht? Dann kann Natur selber als diese wirkliche Ermöglichung nicht ausschließlich dasjenige sein, auf das man sie im dualistischen Sinne bisher als Materie und Physis reduziert hat. Ebenso kann dann nicht der Geist dualistisch abgespalten werden von seinen anorganischen, physischen und psychischen Verwirklichungsbedingungen. Vielmehr tritt er dann als integratives Resultat eines symbolischen Kommunikationsprozesses unter den genannten Verwirklichungsbedingungen hervor. Daher gibt es in Deweys und Plessners Philosophien kein positivistisches Ende der Naturbeherrschung, sondern eine künftig offene, an Erfahrungsdifferenzen gebundene Aufgabe, sich in den personalen Lebensformen einer Antwort auf die qualitativen Brüche in der Natur, ihrer Fraglichkeit, gewachsen zu zeigen. Während Dewey die wirkliche Ermöglichung des Politischen aus dem Öffentlichen funktional versteht, nämlich aus den indirekten Folgeproblemen der kapitalistischen Industrie- und Konsumgesellschaft heraus, entwirft Plessner diese wirkliche Ermöglichung primär aus dem Zivilisationsprozess, in dem erlernt wird, wie mit der Pluralisierung und Individualisierung von Autoritäten verfahren werden kann. Beide Zugänge haben theoretischmethodisch gesehen Äquivalente füreinander, die sich ergänzen können. 